\title{
Installation of the superconducting bus bar system of Wendelstein 7-X
}

\author{
K. Rummel ${ }^{1}$, A. John ${ }^{1}$, L. Hajduk ${ }^{2}$ \\ ${ }^{1}$ Max Planck Institute for Plasma Physics, EURATOM Association, Wendelsteinstr. 1, 17491 Greifswald, Germany \\ ${ }^{2}$ Henryk Niewodniczanski Institute of Nuclear Physics, Polish Academy of Sciences \\ Krakow, Radzikowskiego 152, Poland \\ Corresponding author e-mail: kerstin.rummel@ipp.mpg.de
}

\begin{abstract}
The superconducting bus bar system of the Wendelstein 7-X (W7-X) experiment consists of 121 bus bars and 184 bus bar joints, which provide the electrical and hydraulical connections between bus bars and coils and between different bus bar sections.

The bus bars are made of the same superconductor as the coils. The W7-X superconductor is made of $243 \mathrm{NbTi}$ copper stabilized strands enclosed in an aluminum jacket. The bus bars were cut, bent and partially insulated before they were delivered to the assembly area of W7-X.

The assembly of the bus bars was a logistical and technical challenge because of numerous interfaces and geometrical boundary conditions.

The complexity of installation required extensive quality assurance and assembly plans, where each work step had to be precisely defined.

The assembly of all bus bars and bus bar joints has been finished. The installation of the current leads which connect the bus bar system to the power supplies is underway.
\end{abstract}

Keywords—bus bar installation, assembly, joint, current lead

\section{INTRODUCTION}

The magnet system of W7-X comprises 70 superconducting coils arranged periodically around the plasma axis into five identical modules. The superconducting bus bar system of the Wendelstein 7-X (W7-X) experiment contains five similar bus bar sections and consists in total of 121 bus bars and 198 joints, which provide the electrical and hydraulical connections between bus bars and coils, clamps and current leads (Fig. 1). In total 755 supports and 1500 clamps for the bus bars are required to balance the high mechanical loads up to $11 \mathrm{kN} / \mathrm{m}$, different thermal expansion and displacement of coils (up to $24 \mathrm{~mm}$ ). The bus bar system has been designed for operating currents up to $18.2 \mathrm{kA}$ and for a nominal voltage to ground of $6 \mathrm{kV}$ DC (related test voltage of $13 \mathrm{kV} \mathrm{DC}$ ). To minimize the magnetic stray field the bus bars are routed bifilar wherever possible [1], [2].

The design of the bus bars turned out to be very challenging. Apart from the requirements listed above numerous interfaces and geometrical boundary conditions define a tight space available for the accommodation of the bus bars and their support elements [1].

The bus bars are made of the same forced flow cable-inconduit conductor as the coils. The aluminum jacket of the cable had originally a rectangular profile of $16 \times 16 \mathrm{~mm}$. But the square shaped cross section was machined into an almost round one to allow better three dimensional bending. The electrical insulation of the bus bars consists of Kapton ${ }^{\circledR}$ foils, embedded in epoxy resin impregnated glass fiber fabric [1]. The ends of the bus bars are free of any insulation and must be insulated during assembly. Moreover the Quench Detection-wires (QDwires) running along the bus bars underneath the insulation have to be connected to the QD-wires leading to the feedthroughs in the outer vessel. The length of the bus bars vary between 4.5 and 16 meters.

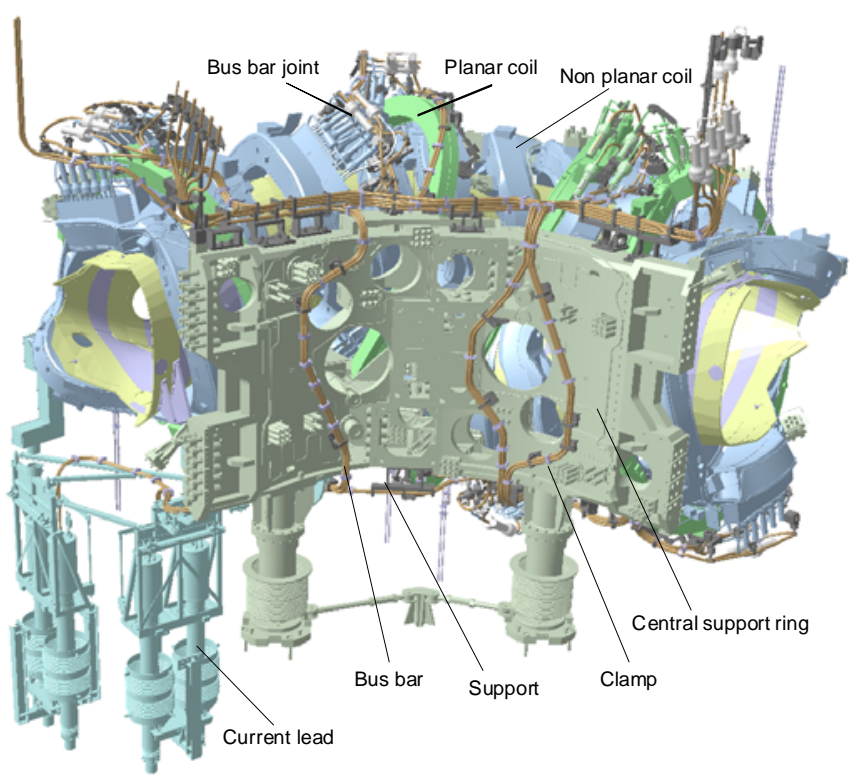

Fig. 1. Schematic view on the magnet system of one module

The bus bar joints provide the electrical and hydraulical interconnection between bus bars and coil terminals and between different bus bar sections. The joints have been designed and qualified for an electrical resistance less than $5 \mathrm{n} \Omega$ [3]. Several tested samples have shown resistances less than $1 \mathrm{n} \Omega$. The housing of the joint has been designed to withstand a pressure of $17 \mathrm{MPa}$. This corresponds to the expected pressure jump of the Helium after a quench in a superconducting coil and to the design pressure of the 
superconductor itself. The joint housings (Fig. 2) are made of stainless steel. Transition pieces provide the material transition from the aluminum jacket to the stainless steel housing. The joint housing consists of a bottom where the superconductors enter the joint and a conical cylindrical cover. The cover will be screwed inside the bottom and welded to the bottom by a lip weld [4]. To allow possible repairs the joints are completely de- and remountable without damaging the superconducting strands. That means the insulation can be removed without destroying the joint housing. The lip weld of the joint housing can be cut with a small milling machine and the cover can be unscrewed. Afterwards the solder (60/40 Tin/lead) of the joints can be heated up. This allow to separate the two strand bundles of the two superconductors without the need to cut the strands. This procedure allows a re-assembly of a joint at the same place which represents a very important feature in the overcrowded W7-X cryostat.

The bus bar joint connects not only two superconductors but also acts as connection and junction point for the QD-wires from the bus bars and coils.

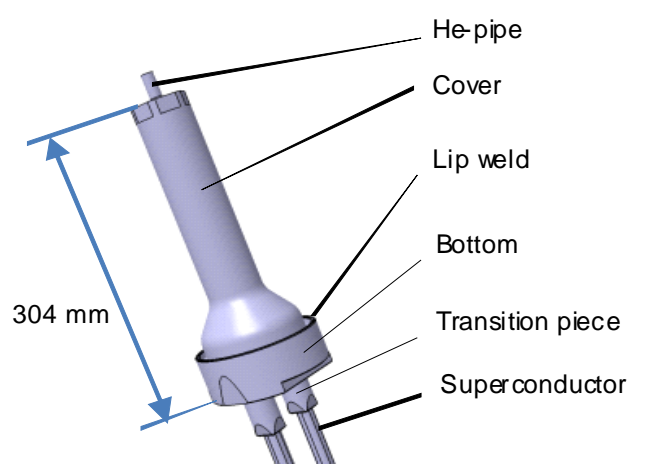

Fig. 2. Schematic of a bus bar joint housing

To energize the superconducting coils the bus bar system must be connected to the 14 current leads (two per electrical circuit). These current leads are the electrical connection between the power supplies outside the cryostat and the superconducting bus bar system inside the cryostat. The connection between the bus bar and the current lead (CL) is the so-called CL-joint. The cold contact of the CL has a flat gold plated surface. The joint box wherein the triplets of the bus bar are soldered will be pressed tight to the cold contact of the CL by a steel clamp (Fig. 3, left hand side). Finally the vacuum cylinder will be put over the CL-joint because all components of the CL are in a vacuum chamber separated from the cryostat vacuum of W7-X (Fig. 3, right hand side).

In a framework of a cooperation between the Max Planck Institute for Plasma Physics (IPP), Greifswald, Germany and the Forschungszentrum Jülich (FZJ), Germany the FZJ has taken over the design and the manufacturing of the pre-bent bus bars, the supports, clamps and bus bar joint housings. The delivery of the tested single bus bar sections, supports, clamps and bus bar joint housings took place just in time according to the module assembly progress.
The IPP was responsible for the development and qualification of the strand connection inside the joints, the CLjoint, the insulation system of the bus bar ends and joints and for the assembly of all components mentioned above.

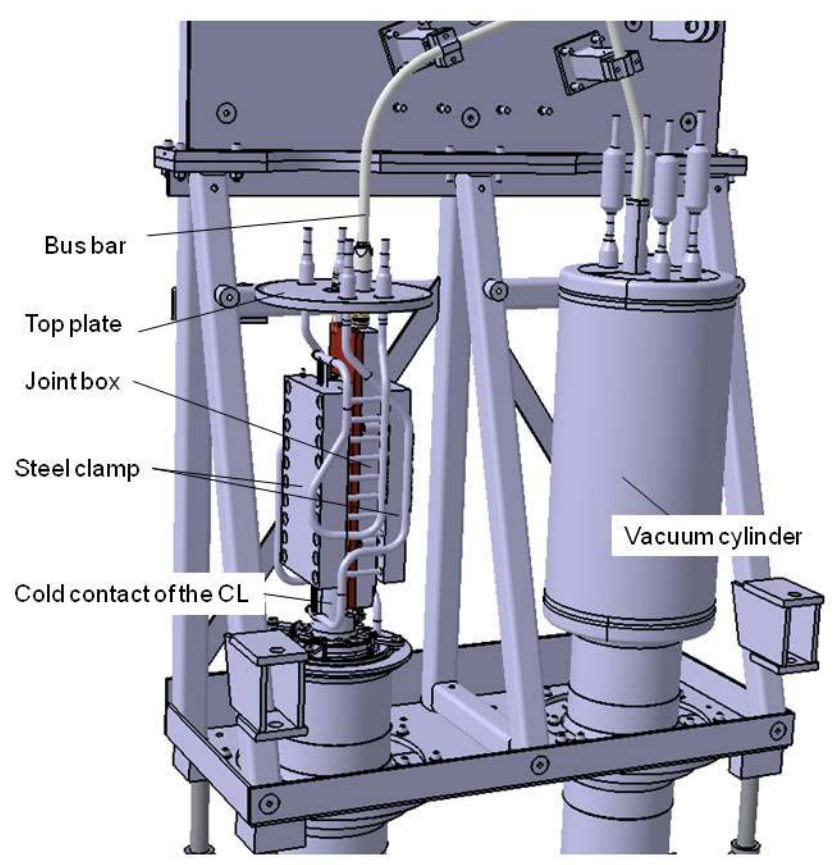

Fig. 3. Schematic view of two CL-joints at the cold end side of the CLs.

The installation of the first bus bar section started at the beginning of 2008 after an intensive and comprehensive qualification process at mock-ups which simulate the real situation regarding space and orientation. The assembly personnel were trained at these mock-ups. Most of the assembly work was done by experienced workers of the Institute of Nuclear Physics Krakow (Poland). The installation turned out to be logistical and technical challenges because of numerous working steps and numerous constraints.

\section{SEQUENCE OF INSTALLATION}

The installation sequence of the bus bars had to follow the assembly sequence of the coils. At first a half module of the magnet system, which represents one tenths of the total magnet system, has been assembled. It contains five non planar and seven planar coils and the part of the central magnet support ring [5]. After that two half modules have been connected, forming a module, which represents one fifths of the machine. Then bus bar installation started. The assembly of the bus bar system consists of the six steps
A. pre-assembly of bus bars in W7-X
B. bus bar preparation
C. final assembly of supports, bus bars and clamps
D. mounting of bus bar joints
E. interconnection of bus bar sections 
F. connecting of the bus bars to the current leads.

\section{A. Pre-assembly of bus bars in W7- $X$}

The pre-assembly of bus bars is necessary because the bus bars needs to be adjusted at their ends to the as-built dimensions of the coils to fit into the joint housings which will be installed later after final assembly of bus bars. The bus bar ends had to be bent and adjusted in a way that they fit exactly into a template of a joint because afterwards they are insulated and a bending of an insulated conductor is impossible without damaging the insulation. It has to be noted that the ends of the bus bars are free of any insulation in that step which allows the bending work.

Apart from the need for bending of bus bars the aluminum welding of the transition piece to the superconductor is very challenging, especially in overhead-position welding. Furthermore the distance to the neighboring transition piece of the coil terminal is about $20 \mathrm{~mm}$ only. Therefore the weld must be done outside the module in a suitable welding position. The position of the transition piece had to be precisely marked during the pre-assembly of bus bars.

To pre-assemble the bus bars selected fixed supports (Fig. 4) at the central support ring of the magnet system were mounted and all bus bars of one module were temporarily installed and fixed with auxiliary clamps. These supports define the overall position of the bus bars. Furthermore about 80 different adjustable supports per module which hold one bus bar or a pair of parallel bus bars were installed at the coils. These supports can be aligned in all 6 degrees of freedom and balance the mutual displacement of the coils and the central support ring. An example of such adjustable support is shown in Fig. 5. The sliding of the bus bars along the bus bar direction is allowed at all supports to avoid high thermal stress in the bus bars during cool-down [2].

To avoid clashes with components which will be installed later the required local accuracy of all bus bars is less than $2 \mathrm{~mm}$. Most of the supports had to be installed with assistance of metrology. The alignment of the supports with an accuracy less than $2 \mathrm{~mm}$ was very time consuming [5].

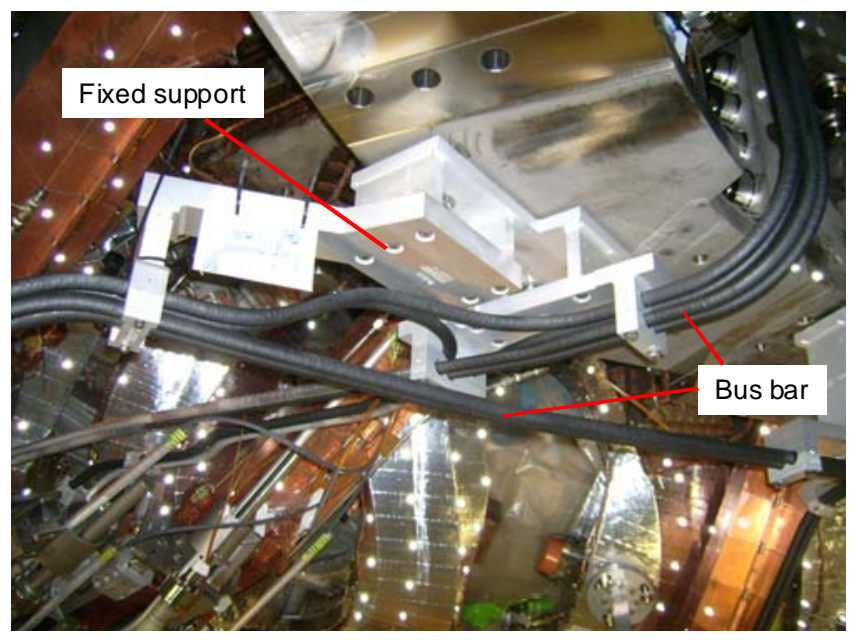

Fig. 4. Fixed support at the cental support ring

In addition, the positions of clamps had to be marked on the bus bars. Depending on the number of bus bars there are single, double and multi clamps (for 6 bus bars). One bus bar has to be firmly fixed with sleeves in the clamp while the other bus bars can slide inside the clamp [2]. The sleeves for the clamps had to be glued on the bus bars during the bus bar preparation.

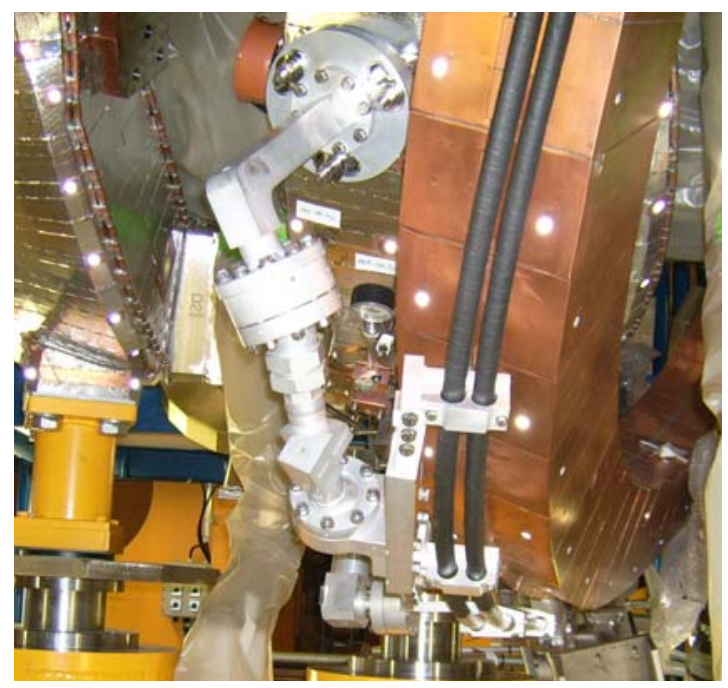

Fig. 5. Adjustable support for two bus bars

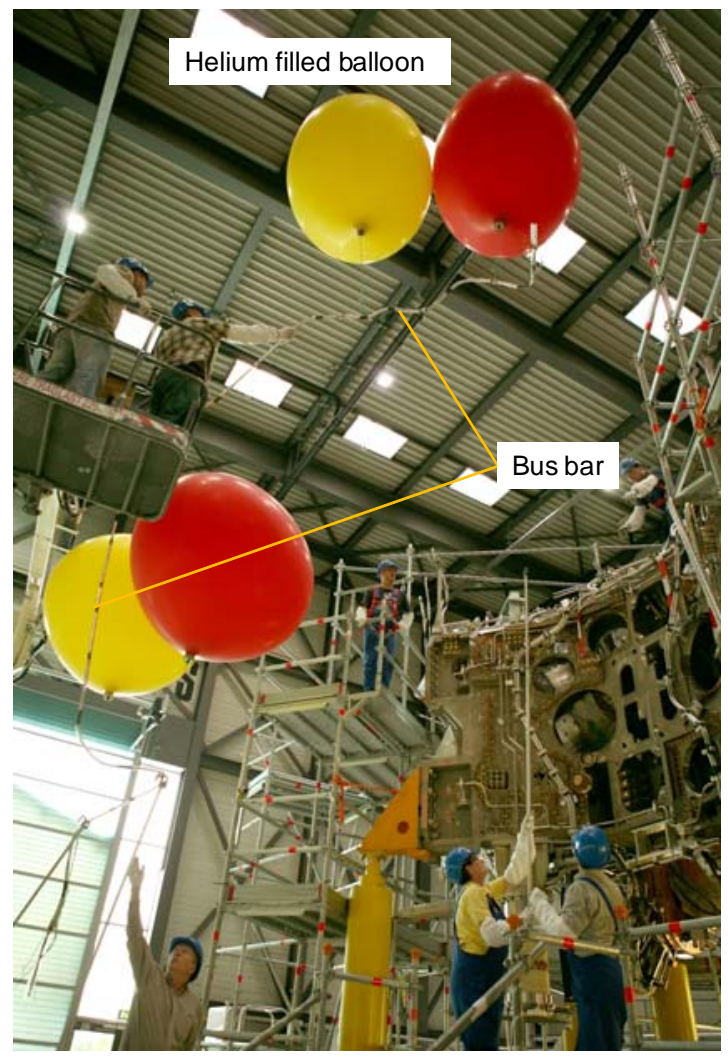

Fig. 6. Transportation of one bus bar to the module 
Special care was taken to avoid deformations and damages during the transport and assembly of the 3D-bent up to $16 \mathrm{~m}$ long bus bars. Helium filled balloons compensating the weight during these activities and allowed damage-free handling during the sophisticated assembly (Fig. 6). This handling procedure was qualified during the manufacturing of the bus bars at FZJ.

\section{B. Bus bar preparation}

Afterwards the bus bars were disassembled and transported in a preparation area outside the module. The ends of the bus bars were cut to their final length and customized for the connections to the coils, afterwards the sleeves for the clamps were glued to the bus bars.

Among about 80 working steps, the preparation includes welding of transition pieces for the transition from the aluminum jacket of the superconductor to the steel joint housing and dismantling of the jacket and tinning of strands in preparation of the joint assembly.

The qualification process of this aluminum weld between the bus bar and the transition piece (Fig. 7) was very extensive and lasted for about a year, because the allowable temperature to the transition piece and to the superconductor is limited. The TIG welding must be precisely carried out according to the welding procedure specification. Before performing the welding at the bus bars a sample from the same bus bar conductor (cutted over length) had to be welded to a dummy of transition piece. Only after successful visual inspections and metallographic sections the process for the conductor was released. A leak test was made for each weld seam.

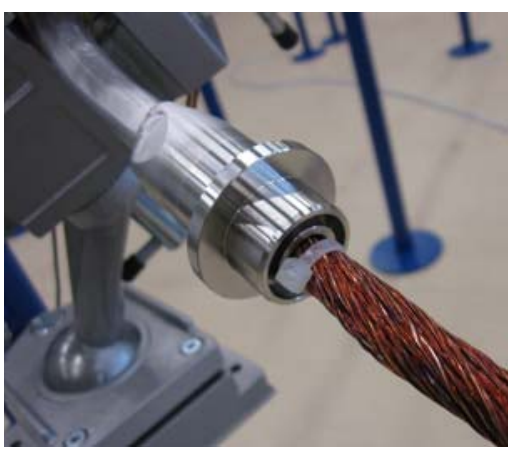

Fig. 7. Transition piece at the bus bar end

A voltage tap (QD-wire) for the quench detection was soldered in a bolt of alumium. Then the bolt was welded by capacitor discharge stud welding to the aluminum jacket of the bus bar [6]. This procedure secures on one hand a reliable connection and avoid on the other hand an undesirable heat impact to the superconductor. The proper connection of these voltage taps is important to ensure the detection of a quench and the safety of W7-X. Electrical measurements were done for each voltage tap.

A last important working step was the electrical insulation of the bus bar ends up to the transition piece. According to [7] the insulation of the customized bus bar ends was carried out in two steps. At first the transition piece was insulated with an insulation cap which consists of two half shells of premanufactured G10. The QD-wires from the bus bar were fed through this insulation cap. In a second step the uninsulated bus bar end was insulated with Kapton ${ }^{\circledR}$ foils, embedded in epoxy resin impregnated glass fiber fabric.

A finally performed electrical test at $13 \mathrm{kV}$ with local test chambers ensures the quality of the insulation of bus bar ends and QD wires under vacuum and under reduced pressure (Paschen conditions).

\section{Final assembly of supports, bus bars and clamps}

The customized bus bars has been assembled again and finally fixed in the supports and clamps. This step required a strong interaction with other installation work. Especially the installation of the stainless steel pipes for the liquid Helium uses nearly the same space and also the pipes were prebended and had to be adjusted by hand to the final geometry. Fig. 8 shows the bus bars sharing the restricted space with the Helium pipes on the upper central support ring. In general first the main cryo pipes were installed, then the bus bars were installed and finally another layer of small Helium pipes have been installed. This interference required a proper organization as well as special care in handling in order not to the damage the bus bar insulation or supports. Comprehensive configurationcontrol measures were necessary to avoid clashes with neighboring components.

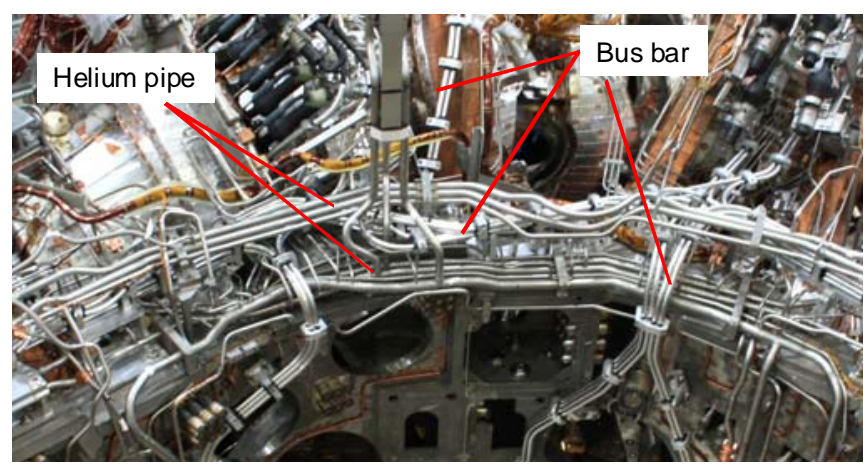

Fig. 8. View on the upper central support ring

\section{Mounting of bus bar joints}

Twenty-eight bus bar joints to the coils had to be mounted per module and the connections to the helium piping had to be welded.

The mounting of joints was one of the most critical activities of the assembly of W7-X. The poor access to the terminal ends of coils and bus bars, different orientation of joints and a very tight environment have been hampered the assembly of joints. At first the transition pieces of the coil and bus bar terminals have been TIG welded in the bottom of the joint housing. Then each of the 81 triplets of the bus bar conductor have been soldered to one triplet of the coil conductor (Fig. 9). The soldered pairs of triplets have been bundled and compacted in a steel clamp [3]. Finally the cover 
have been put over the clamp and welded to the bottom. Leak test after each assembly step confirmed the tightness of the joint housing.

The achieved electrical resistance of the strand connection depends directly on the quality of work. A resistances of more than $5 \mathrm{n} \Omega$ leads to excessive heat and could cause a quench. Therefore the working steps of the strand connection were intensively trained at mock-ups which simulate the real situation regarding space and orientation. As electrical tests to check the resistance during and after mounting are impossible thorough numerous visual inspections are important to ensure the quality. Several samples made on-site at mock-ups and reassembled samples were tested at the Efremov Institute in Russia and confirmed the specified resistance less than $5 \mathrm{n} \Omega$.

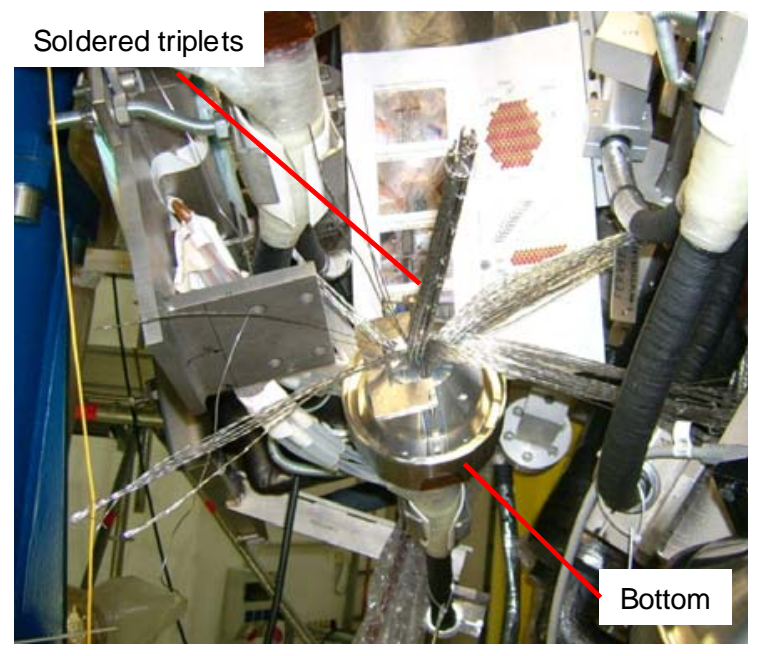

Fig. 9. Bundling of soldered triplets

The joint housing have been electrically insulated with handmade wrappings and cut-offs of epoxy resin impregnated glass fiber fabric (Fig. 10). Larger areas have been insulated with premanufactured G10 pieces embedded in the glass fabric insulation. An additional layer of Kapton ${ }^{\circledR}$ foil is underneath the fabric insulation. The minimum thickness of the insulation is $5 \mathrm{~mm}$. Special care was given to the transition from the insulation caps to the bottom of the joint housing and to the conical area of the cover. These areas are extremely difficult to insulate because of sharp edges, conical shapes and the poor access. These areas were stepwise insulated by overlapping cut-outs of glass tape. To keep a high pressure at the cone and at the insulation caps during curing of the resin some layers of nylon peel ply have been very tightly wound around the cone and insulation cap and fixed at a neighbouring component. The laminate on the bottom was pressed with a special tool against the top of the cover [7].

Then the QD-wires welded to the conductor have been soldered to the QD-wires running through the cryostat to the feedthrough in the outer vessel. In addition the insulation of the soldered connections has been carried out [7].
Paschen tests of all insulation work have been made in local chambers under Paschen conditions on-site .

Finally, the bus bar ends, coil terminals and joints have been covered with a semi-conductive paint. The quality of this painting was checked by samples.

\section{E. Interconnection of bus bar sections}

The interconnection of the bus bar sections started after the neighboring module was put on the machine base of W7-X. The adjacent bus bars of each single bus bar system have been connected with the same joints as the coil terminals. 2012.

The last interconnecting joint was finished at the end of

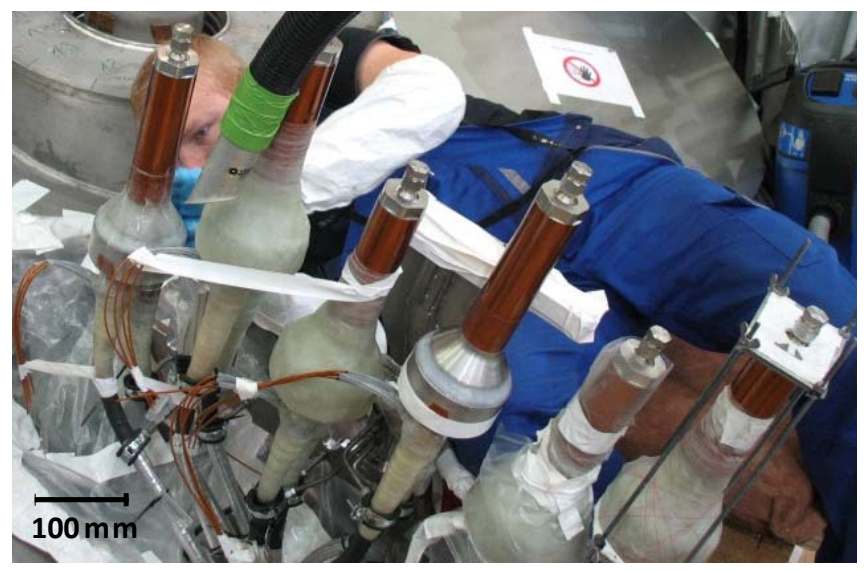

Fig. 10. Insulation of the last joints at the module section area

\section{F. Connection of the bus bars to the current leads}

After completition of the magnet system, i.e. connection of all five modules of W7-X the assembly of the current leads started in autumn 2012. The current leads will be installed in an opening at the bottom side of the cryostat.

The assembly of the current lead including the assembly work of the CL-joint and the electrical insulation has been qualified and trained at a 1:1 mock-up.

Before the current lead will be installed the CL-joint at the bus bar had to be prepared in its final position. First the top plate of the CL (Fig. 3) will be moved over the bus bar end and will be kept in this position until the joint box is prepared. Fig. 11 shows the schematic view of the structure of the joint box. The bus bar will be customized at its end, i.e. removing of jacket and tinning of triplets. Then the joint box housing including the aluminum-stainless steel transition piece will be put over the dismantled bus bar and welded to the bus bar jacket. The joint box housing is machined from an explosion welded piece of stainless steel and copper. The copper side of the joint box is gold plated to avoid the oxidation of the surface. In the next step the triplets of the bus bar will be put into the grooves of the copper of the joint box housing and pressed with the copper plate. The triplets will be soldered with 
60/40 Tin/lead solder into the grooves and at the copper plate by heating up the joint box housing. Then the cover of the joint box will be pressed against the housing and closed with a lip weld seam. Finally the copper side from the joint box will be gold plated.

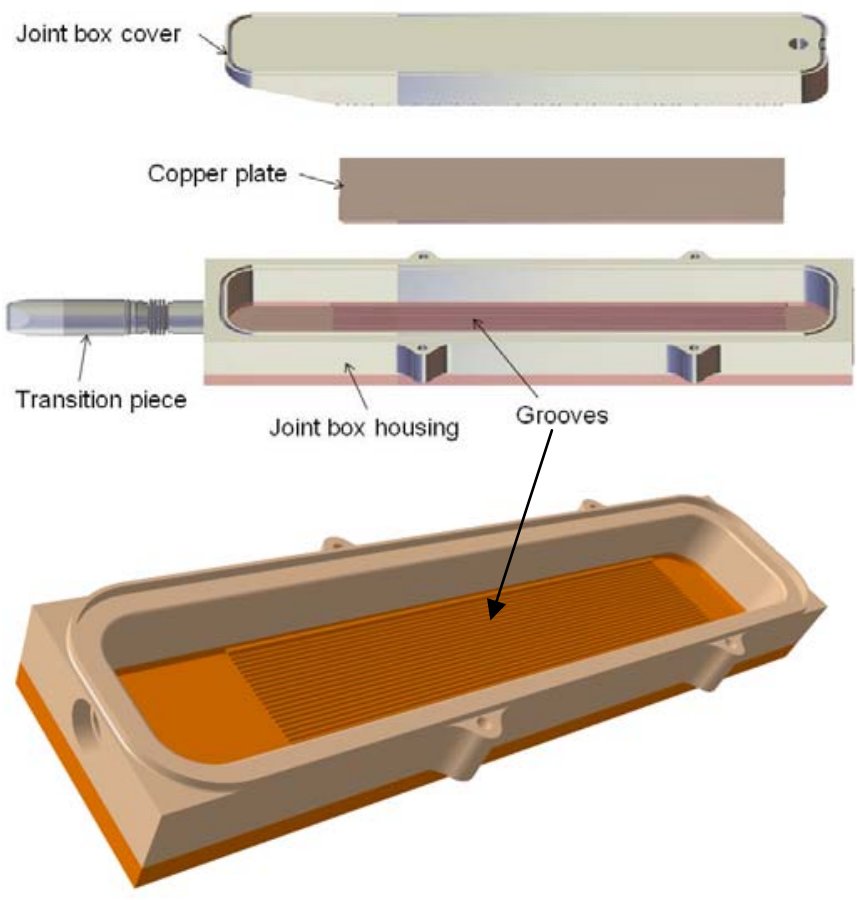

Fig. 11. Joint box at the current lead. Top: Structure of the joint box. Bottom: View on the grooves in the housing

Then the current lead will be assembled with assistance of metrology into their final position. The gold plated side of the joint housing will be pressed tight to the cold contact of the CL by a bolted steel clamp (Fig. 3, left hand side). An insert of indium wires between the two surfaces minimize the transition resistance.

After mounting the CL-joint the QD-wires will be connected to the feedthrough in the top plate and an outside insulated vacuum cylinder will be put over the joint and welded to the top plate (Fig. 3, right hand side). The insulation on the cylinder already exists when the insulation work at the CL-joint starts. The transition from the insulation of the bus bar to the insulation of the top plate is based on the same principle as the insulation of the bus bar to the bus bar joint (Fig. 12). The top plate will be insulated with premanufactured G10 pieces and epoxy resin impregnated glass fiber fabric [7].

The assembly of the 14 (7 pairs) current leads is one of the last activities at the outer vessel. By July 2013, three pairs of current leads were installed and successfully electrical tested at high voltage under Paschen conditions.

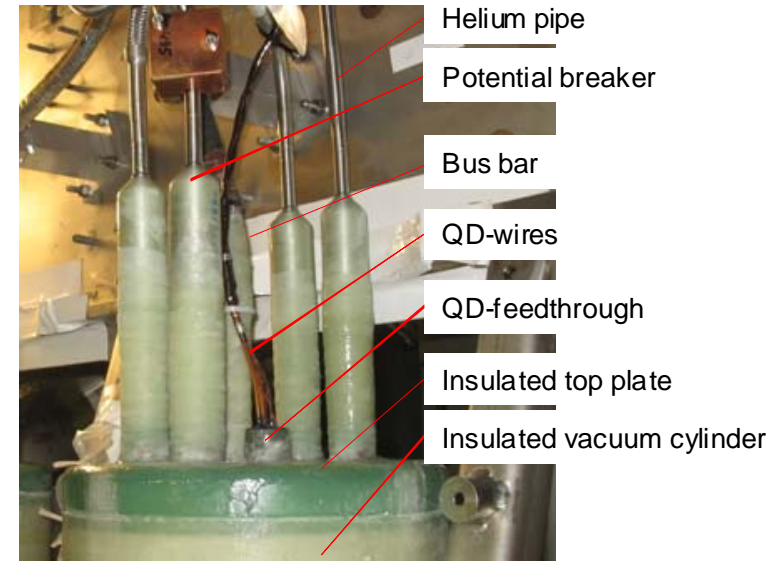

Fig. 12. Joint at the current lead

\section{PlanNing AND Quality Assurance}

The complexity of installation required extensive quality assurance and assembly plans, where each working step is precisely defined. The description of work is given in detailed working and test instructions. For the installation of the bus bar system in total about 100 quality assurance and assembly plans and working instructions had to be developed and permanently optimized.

Major steps have been qualified at first on the work bench and later in a test stand simulating the real space conditions, e.g. overhead insulation work or welding work with mirrors. Also during the work at W7-X machine each assembly step was checked and documented by signed test protocols or released hold or notification points. Main principle of the quality assurance during the assembly was the four-eyesprinciple. That means that a supervisor or the shift leader had to check all performed working steps.

In total 444 non conformities were discovered. All of them have been solved without negative influence of the planned operation of W7-X magnet system.

To meet the tight time schedule for the assembly of W7-X the regular work was done in two shifts. Most of the high voltages tests must be done during breaks or in a third shift during the night because of safety regulations for high voltage tests.

Through learning effects and optimization of work flow and equipment the duration of bus bar assembly and helium piping of one module was reduced from 60 weeks to 37 weeks for the last module [5].

\section{SUMMARY}

The superconducting bus bar system of W7-X connects the coils with each other, provides the connection to the current lead inside the cryostat and connects the five magnet modules.

In total about $1200 \mathrm{~m}$ of conductor were necessary to manufacture the 121 bus bars. The installation of the bus bars was one of the major challenges during the assembly of W7-X. 
Especially the three dimensional routing and the very tight space situation required a complex and time consuming assembly procedure including a pre-assembly of each bus bar in W7-X to adjust it to the as-built geometry of the other components. The 184 bus bar joints had to be made directly on-site. Therefore an intensive qualification program had been established. Extensive quality checks after nearly every assembly step turned out to be necessary to ensure the required quality.

The first bus bar section was installed in 2006, the assembly of the entire bus bar system was finished with the last bus bar joint end of 2012. The connection of the bus bars to the current leads is underway. Three of the 7 pairs of current leads are finally connected. The last pair will be accomplished in spring 2014.

\section{REFERENCES}

[1] O. Neubauer, A. Charl, G. Czymek, B. Giesen, M. Sauer, L. Scheibl, J. Schruff, R. Schick, A. Panin, A. John, S. Jung, K. Rummel, L. Wegener, "The busbar system for Wendelstein 7-X prepared for assembly and operational loads," Fusion Engineering and DesignVolume 84, Issues 7 11, June200 9, pp. 1416-1419.
[2] B. Giesen, A. Panin, T. Boguszewski, S. Brons, A. Charl, G. Czymek, A. John, O. Neubauer, M. Sauer, R. Schick, J. Szlagowska, J. Wolters, "Structural evaluation of the busbar system of Wendelstein 7-X stellarator," Fusion Engineering and DesignVolume 82, Issues 5-14, October 2007, pp. 1591-1598

[3] K. Rummel, M. Czerwinski, F. Hurd, A. John, H. Lentz, G. Czymek, B. Giesen, F. Harberts, S. A. Egorov, V. E. Korsunsky, I. Y. Rodin, P. Bruzzone, B. Stepanov, M. Vogel, "Test results from the full size prototype test of W7-X joint," Fusion Engineering and Design, Volume 82, Issues 5-14, October 2007, pp. 1526-1531.

[4] G. Czymek, B. Giesen, F. Harberts, A. Panin, M. Lennartz, U. Reisgen, W. Schuster, J. Wolters, K. Rummel, M. Czerwinski, H. Lentz, M. Ebner, "Design aspects of the joints for the bus bar system of the Wendelstein 7-X stellarator," Fusion Engineering and DesignVolume 82, Issues 5-14, October 2007, pp. 11467-1472.

[5] L. Wegener and W7-X team, "Experiences from the assembly of the magnet system for Wendelstein 7-X," IEEE Transactions on applied superconductivity, vol. 22, No. 3, 2012, 4201004

[6] K. Rummel, A. John, "Insulation of the coil and bus bar ends during assembly of W7-X," IEEE Transactions on applied superconductivity, vol. 16, No. 2, 2006, pp. 751-754.

[7] K. Rummel, A. John, Z. Sulek, "Design principles for handmade electrical insulation of superconducting joints in W7-X," Fusion Engineering and Design Volume 88, Issues 9-10, October 2013, pp. 1623-1626. 